\title{
Structure, validity and reliability of the Children's Attitudes Towards Integrated Physical Education-Spanish version (CAIPE-SP)
}

\author{
David Cordente-Mesas ${ }^{1}$, Sixto González-Víllora ${ }^{1}$, Martin E. Block², \\ and Onofre R. Contreras-Jordán ${ }^{3}$
}

${ }^{1}$ Faculty of Education of Cuenca, University of Castilla-La Mancha, Spain; ${ }^{2}$ University of Virginia, United States of America; and ${ }^{3}$ Faculty of Education of Albacete, University of Castilla-La Mancha, Spain

\begin{abstract}
The main aims of the present study is to translate, carry out and test the validity and reliability of a transcultural adaptation of the Children Attitudes towards Integrated Physical Education - Revised CAIPE-R (Block, 1995) into the Spanish language in order to be used in Spain. Participants were 791 primary school students without disabilities (393 males and 398 females, aged between 9 to 13 years old, mean age $10.80 \pm 0.739$ ). The CAIPE-R measures the attitudes that children without disabilities have towards the inclusion of children with disabilities in their general physical education (GPE) lessons. Results confirm a structure of three components of the scale CAIPE-SP accounting for $35.982 \%$ of the variance. The estimation of reliability for the subscales was $.812, .470$ and .374 , respectively. Taking into account the obtained results, the transcultural adaptation of the scale CAIPE-R into Spanish supposes a valuable contribution to the research about the perception of disabilities in physical education.
\end{abstract}

Keywords: inclusion, education, integration, visual impairment, adapted physical education, CAIPE-R

\section{Introduction}

The education system regarding students with disabilities has been deeply remodeled in the last thirty years with a focus on closing special schools in favour of including students with disabilities in general education classrooms within general education schools (Block, 2007; Campos, Ferreira, \& Block, 2013; Klavina \& Kudláček, 2011; Lienert, Sherrill, \& Myers, 2001; Lipsky \& Garnter, 1997; Meegan \& MacPhail, 2006; Smith, 2004). Governments around the world have been reinforcing this trend. For instance, the U.S. has been promoting the inclusion of students with disabilities for many years, and recent data shows that $95 \%$ of students with disabilities are educated in general education schools (U. S. Department of Education, 2013). Similarly, Strategy 2020 in the European Union establishes that fighting against social exclusion is a main objective (European Commission, 2010), seeking to develop innovation programmes designed to face discrimination towards people with disabilities, although substantial improvements are still needed towards the inclusion of students with disabilities into physical education classes (Klavina \& Kudláček, 2011).

In Spain the government has passed laws supporting the placement of children with disabilities into general education classes (Spanish Ministry of Education, Culture and Sports, 2006; 2013) showing a political effort towards inclusion. The result has been an increase in the number of students with disabilities that are educated in general education schools, up to $80.3 \%$ of the total; with students with visual impairment obtaining the highest percentage of integration into general schools, $95.7 \%$, compared to any other population with disability (Spanish Ministry of Education, Culture and Sports, 2014a; 2014b). Other programmes have been developed, such as the ones led by the Centre of Inclusive Sport, which led a strong activity to promote inclusive sports in schools (PérezTejero, 2013) or the ones led by the Spanish Association on Adapted Physical Activity and Sports (Reina, Mendoza, Sanz, \& Pérez-Tejero, 2013).

The model of jointly educating students with and without disabilities has had many different names beginning with mainstreaming, then changing to integration, and finally being named inclusion (Block, 2016). But this process not only is centered in educating the students jointly, but also in providing the educational support, services and materials that allow students with disabilities to become an integrative part of the daily school life (WEAC, 2009). Promoting social inclusion among their peers without disability 
must be carried out in order to decrease negative attitudes toward the disability (Verdugo, 2009). In this line, international legislation now promotes and considers the process of inclusion as compulsory policy that shall be internationally developed (United Nations, 2006), as it is considered to have many benefits both for students with and without disabilities (Panagiotou, Evaggelinou, Doulkeridou, Mouratidou, \& Koidou, 2008).

Having peers accept a classmate with a disability is critical for successful inclusion in both the general education classroom as well as in general physical education (Block \& Obrusnikova, 2016). In fact, the inclusion of students with disabilities into general physical education has become a growing trend (Block, 2016), being an effective academic area which offers opportunities for social acceptance of students with disability (Block, 2007). Research clearly shows that, without peer acceptance, students with disabilities may not have a successful experience in physical education, have limited social learning opportunities, and may even be rejected and bullied by peers (Goodwin \& Watkinson, 2000; Hutlzer, Fliess, Chacham, \& Van den Auweele, 2002; Place \& Hodge, 2001). Fortunately, research suggests that many children without disabilities have positive attitudes toward including classmates with disabilities in physical education and sports activities (Block, 1995; Block \& Malloy, 1998; McKay, Block, \& Park, 2015; Modell, 2007; Murata, Hodge, \& Little, 2000; Obrusnikova, Block, \& Dillon, 2010; Townsend \& Hassall, 2007; Verderber, Rizzo, \& Sherrill, 2003). For example, Block and Malloy (1998) found that girls without disabilities ages 11-13 overwhelmingly accepted a child with a disability into their competitive, fast-pitch softball league. Furthermore, they were willing to allow modifications to make sure this peer was successful.

Attitudes of students without disabilities clearly plays an important role in the success of inclusion in physical education, especially with respect to the predisposition to accept, coexist and cooperate with their classmates with disabilities (Pérez-Tejero, Ocete, Ortega-Vila, \& Coterón, 2012; Slininger, Sherrill, \& Jankowski, 2000). However, many peers without disabilities may have negative attitudes towards having a peer with a disability in their physical education class, because they have no experience with peers who have disabilities (Lindsay \& McPherson, 2012). Some peers may not want students with disabilities in their physical education classes, because they feel that these students will slow down and disrupt their physical education programme (Block \& Obrusníková, 2007).
Others may be a little scared of students with disabilities, while others may be sympathetic towards students with disabilities but not know how to interact with them. Thus, understanding the attitudes of students without disabilities is a critical part of the process of including students with disabilities into general physical education, as it is one of the main factors intervening in the process of school inclusion (Kudláček, 2006). It can be stated that, in the achievement of this goal, formative programmes can contribute to positively modify the attitudes of people without disabilities (Aguado, Flórez, \& Alcedo, 2004).

\section{Children's Attitudes towards Inclusion in Physical Education - Revised (CAIPE-R)}

The Children's Attitudes towards Inclusion in Physical Education - Revised (CAIPE-R) (Block, 1995; Obrusníková, Válková, \& Block, 2003) is one of the most widely used scales to measure the attitudes of students without disabilities towards the inclusion of their classmates with disabilities in general physical education. This instrument was developed with the objective of measuring how students without disabilities feel about the idea of having classmates with disabilities in their physical education classroom. This instrument is very valuable for those teachers who would like to know the impact that inclusion produces on their students without disabilities (Campos et al., 2013). Validation of the original scale was firstly carried out with 44 students of sixth grade, 10-12 years of age. Based on analysis of these original results, a revised version of the scale was tested on 208 students of the same age.

The final version (CAIPE-R) has been used in studies in Spain (Cordente, González-Villora, PastorVicedo \& Contreras-Jordán, to be published), the USA (Ellery \& Rauschenbach, 2000; Obrusníková et al., 2003), Belgium (Van Biesen, Busciglio, \& Vanlandewijck, 2006), Israel (Hutzler \& Levi, 2008), Czech Republic (Ješina et al., 2006; Kudláček, Ješina, \& Wittmanová, 2011; Liu, Kudláček, \& Ješina, 2010), and Greece (Panagiotou et al., 2008; Xafopoulos, Kudláček, \& Evaggelinou, 2009). Despite its adaptation to different cultures and languages, all studies registered positive values of internal consistency. For instance, Hutzler and Levi (2008), obtained values of $\alpha=.77$ and $\alpha=.62$, in the general and in the sport specific subscale, respectively. Exploratory Factor Analysis (EFA) was applied and a bi-factor solution was computed accounting for $42 \%$ and $48 \%$ of the variance, respectively. The version of Kudláček et al. (2011), for instance, obtained a Cronbach's alpha of $\alpha=.84$ in the complete scale. The version of Campos et al. 
(2013), also carried out measurements of the Confirmatory Factor Analysis, CFI and AGFI index values were .81 and .92 , respectively.

Adaptation of the instrument into the Spanish language had not been carried out to date, nor have its properties of internal consistency, validity and reliability been measured. Therefore, the objectives of this study were:

a) to translate, carry out and validate a transcultural adaptation of the original scale (CAIPE-R: Block, 1995) into Spanish language of its use in Spain;

b) to describe the structure of its components;

c) to compare the structure of CAIPE's Spanish version to the original instrument;

d) to test the validity and reliability of the CAIPE's Spanish version;

e) to measure the attitudes of the sample consulted regarding the inclusion of a classmate with disabilities in physical education.

\section{Methods}

\section{Participants}

The study used a probability sampling (incidental type). Researchers asked the cooperation of all primary education schools in the Autonomous Community of Castilla-La Mancha (Spain). Those schools that showed interest finally took part in the study. The final sample included 791 participants comprised of 393 boys and 398 girls between the ages of 9 to 13 years old $(M=10.80 ; S D=0.739)$, representing 15 schools from five provinces (three in Albacete, three in Ciudad Real, three in Cuenca, two in Guadalajara and four in Toledo). Schools were located in both city and rural areas (eight in city areas and seven in rural areas). None of these students had any previous contact with any person with visual impairment in the field of physical education.

\section{CAIPE Questionnaire}

The CAIPE-R includes a description of a student with a disability, a vignette representing the student with disability, seven statements about the inclusion of this student in the physical education classroom, and five statements regarding possible adaptations in team sports that would promote the inclusion of this student. The last five statements are oriented to the adaptation degree to a sport modification in order to include a person with disabilities in that sport played during physical education. Participants express their degree of agreement or disagreement to each statement according to a four-point Likert scale of 4 elements $(4=$ yes, $3=$ probably yes, $2=$ probably no, $1=$ no $)$.

Below the content appearing in the English scale is shown, followed by the statements included in the scale (Block, 1995, p. 69).

Jimmy is the same age you are. However, he cannot walk, so he uses a wheelchair to get around. Jimmy likes playing the same games you do, but he does not do very well in the games. Even though he can push his wheelchair, he is slower than you and tires easily. He can throw a ball, but not very far. He can catch balls that are tossed straight at him, and he can hit a baseball off a tee, but he cannot shoot a basketball high enough to make a basket. Because his legs do not work, he cannot kick a ball.

When listening to the sentences, think about Jimmy.

\section{General Statements}

1. It would be OK having Jimmy in my P.E. class.

2. Because Jimmy needs help to play sports, he would slow down the game.

3 . If we were playing a team sport such as basketball, it would be OK having Jimmy on my team.

4. P.E. would be fun if Jimmy were in my P.E. class

5. Jimmy should have special physical education with other kids who have similar problems.

6. If Jimmy were in my P.E. class, I would talk to him and be his friend.

7. If Jimmy were in my P.E. class, I would like to help him practice and play the games.

Sport-Specific Statements (referenced to softball for this particular school)

1. Jimmy could hit a ball placed on a tee.

2. Jimmy could have someone help him run to first base.

3. The distance between home and first base could be shorter for Jimmy.

4. Someone could help Jimmy when he plays in the field.

5. If the ball was hit to Jimmy, the batter could only run as far as second base.

A vignette with an image of a person on a wheelchair was included as a complementary support to the text, next to the answers sheet, so participants could see it while answering the questions.

CAIPE-R was designed to be administered to a group. The teacher reads aloud the main description, encouraging students to imagine this child with 
disabilities included in their physical education class. Then, each student receives a sheet with the 12 statements, which they have to provide their opinion regarding their strength of agreement or disagreement towards each statement. Furthermore, the scale has two control items ("I live in Illinois" and "We eat lunch at 8:30 a.m."), to confirm if the student answers truthfully and understands how to use the four-point Likert scale. CAIPE-R starts by asking students about their age, gender, school where they study, if someone in their family has any disability or if they have ever been to physical education classroom where there was a classmate with a disability. Once students answer the demographic questions, the teacher reads aloud the description about the student with a disability. Then, the teacher carefully reads the 12 statements twice in order to identify potential comprehension issues that the participants may have.

\section{Transcultural Adaptation and Modification}

CAIPE-R has been translated and validated in several languages including Portuguese (Campos et al., 2013); Hebrew (Hutzler \& Levi, 2008); Czech language (Kudláček et al., 2011; Xafopoulos et al., 2009; Liu et al., 2010); and Greek (Panagiotou et al., 2008). The process of transcultural adaptation and translation into Spanish was carried out taking into account those studies, as well as the indications offered by CarreteroDios and Pérez (2007) and the international standardized recommendations of Beaton, Bombardier, Guillemin and Ferraz (2000). Regarding translation, the applied method was an approach known as inverse translation (Hambleton, 1996; Banville, Desrosiers, \& Genet-Volet, 2000). Two bilingual translators (native Spanish speakers fluent in English) carried out the translation. They worked independently without knowing each other's work, translating the CAIPE-R into Spanish. Once the new Spanish versions were ready, the translators held a meeting to discuss the different aspects that form the questionnaire, obtaining a common and final version. Then, two native English speakers fluent in Spanish carried out the translation from Spanish back to English. These translators did not know the existence of the original instrument CAIPE-R in English), so we can state that four people fluent in both English and Spanish carried out the translation from the original version into Spanish.

A committee of experts validated the adaptation and translation process. The requirements to become a member of the committee were: to have at least six years of research and teaching experience and hold a $\mathrm{PhD}$ in Education. The committee tried to have the cooperation of professors from both physical education and inclusive education fields. The final committee was comprised of four experts, two had at least six years of research experience in physical education and two with at least six years of experience in special education. Each member of the experts group compared independently the original model (CAIPE-R) and the new version (CAIPE-SP). They then carried out an equivalence analysis between the two instruments. The opinion of the group is of high acceptance towards the new instrument.

According to Block (1995), CAIPE-R is generalizable to more than one type of disability, including visual impairment. A description of a child with visual impairment was used for the present study. However, we decided not to use a vignette, following a similar format as Kudláček et al. (2011). The draft version of the CAIPE-SP was pilot tested with 12 participants of the sixth academic year of primary education. Debate and discussion groups were carried out. Participants of the pilot study understood the questionnaire satisfactorily. The final CAIPE-SP was composed of a total of 14 items. Two of these items confirm that the student comprehended the scale when reading it (I live in Cuenca and The school normally starts at 9 a.m.). These two items were located at the beginning of the scale. Similar to the original scale, there are seven statements regarding the general attitude towards having a classmate with visual impairment in the physical education. These seven statements compose the general scale in the original CAIPE-R. Then there are five statements that comprise the sport specific scale measuring the degree in which students agree with adaptations in the game "kickball" or running while practicing athletics to facilitate the integration of the classmate with visual impairment. It has been estimated that the required time to answer it is 10 minutes. As noted earlier, CAIPE-SP uses kickball as this is a sport played in many GPE programmes in Spain and is close to the original CAIPE-R, which used t-ball (version of baseball). In addition, CAIPE-SP uses athletics for the sentences referred to the fact of running, as it is presented as an ordered activity, and not as a free and without regulation activity. For a better understanding, an English translation of the Spanish statements will be shown in Table 1.

\section{Procedure}

Participants were tested anonymously at the beginning of their GPE class. The corresponding schools had previously approved participation through the consent of their board of directors, as well as 
in the University of Castilla-La Mancha, which is in charge of the programme. After a training process about how to deliver and provide the questionnaire to the participants, the GPE teachers were responsible to carry out the process with their students. These teachers were the ones who transmitted the corresponding instructions and controlled the process of data gathering, creating a standardized atmosphere in every group that composes the total sample. All the students of the different groups participated voluntarily, and no negative incidences were noted. Data have been treated confidentially, highlighting the anonymous aspect in their answers.

\section{Statistical/Data Analysis}

Statistical analysis formed by the study of its validity and reliability was carried out using the software for data analysis SPSS 22. Statistical data (mean,

Table 1

Means and Standard Deviations by Gender in CAIPE-SP items $(N=791)$

\begin{tabular}{|c|c|c|c|c|}
\hline \multirow{2}{*}{ Item } & \multicolumn{2}{|c|}{ Males } & \multicolumn{2}{|c|}{ Females } \\
\hline & $M$ & $S D$ & $M$ & $S D$ \\
\hline $\begin{array}{l}\text { Me gustaría que Juan estuviera en mi clase de Educación Física. } \\
\text { [It would be ok having John in my P.E.]. }\end{array}$ & 3.44 & .764 & 3.52 & .622 \\
\hline $\begin{array}{l}\text { Juan hará que el juego sea más lento y aburrido, ya que necesita ayuda para } \\
\text { jugar. } \\
\text { [Because John needs help to play sports, he would slow down the game]. }\end{array}$ & 2.10 & 1.090 & 1.77 & .939 \\
\hline $\begin{array}{l}\text { Si jugáramos a un deporte de equipo, como el futbol o el balonmano, me gustaria } \\
\text { que Juan estuviese en mi equipo. } \\
\text { [If we were playing a team sport such as handball or soccer, it would be OK } \\
\text { having John in my team]. }\end{array}$ & 3.23 & .928 & 3.40 & .733 \\
\hline $\begin{array}{l}\text { La clase de Educación Física sería divertida y agradable si Juan estuviera } \\
\text { en ella. } \\
\text { [If John were in my P.E. class, P.E. would still be fun and nice]. }\end{array}$ & 3.39 & .841 & 3.51 & .687 \\
\hline $\begin{array}{l}\text { Juan debería ir a clases de Educación Física especiales para otros niños que } \\
\text { también tengan discapacidad visual. } \\
\text { [John should have special P.E. with other kids who have visual impairment]. }\end{array}$ & 3.01 & 1.086 & 2.64 & 1.101 \\
\hline $\begin{array}{l}\text { Si Juan estuviera en mi clase de Educación Física, le hablaría y sería su amigo. } \\
\text { [If John were in my P.E. class, I would try to talk to him and I would be his } \\
\text { friend]. }\end{array}$ & 3.70 & .678 & 3.82 & .493 \\
\hline $\begin{array}{l}\text { Si Juan estuviera en mi clase de Educación Física, me gustaría ayudarle en los } \\
\text { juegos y deportes. } \\
\text { [I John were in my P.E. class, I would like to help him practice and play the } \\
\text { games and sports]. }\end{array}$ & 3.56 & .708 & 3.74 & .616 \\
\hline $\begin{array}{l}\text { Al jugar a béisbol-patada, Juan podría patear la pelota sobre un soporte fijo, } \\
\text { en lugar de en movimiento. } \\
\text { [When practicing kickball, John could kick the ball on a tee, instead that in } \\
\text { movement]. }\end{array}$ & 3.21 & .998 & 3.25 & .857 \\
\hline $\begin{array}{l}\text { Juan podría tener un guía que le ayudara en atletismo. } \\
\text { [John could have someone help him in Athletics]. }\end{array}$ & 3.54 & .762 & 3.51 & .740 \\
\hline $\begin{array}{l}\text { En una carrera, Juan podría salir con ventaja de unos metros. } \\
\text { [In an Athletics Race, John could start with some meters of advantage]. }\end{array}$ & 2.87 & 1.149 & 2.78 & 1.064 \\
\hline $\begin{array}{l}\text { Al jugar a béisbol-patada, alguien podría ayudar a Juan cuando le tocara recibir } \\
\text { la pelota y ésta podría tener cascabeles en su interior. } \\
\text { [When playing kickball, someone could help John when he would have to catch } \\
\text { the ball, which could be a bell ball]. }\end{array}$ & 3.51 & .875 & 3.61 & .732 \\
\hline $\begin{array}{l}\text { Si en el béisbol-patada la pelota se dirige hacia Juan, el pateador no podría } \\
\text { correr más de dos bases. } \\
\text { [If the ball was hit to John, the kicker could only run as far as second base]. }\end{array}$ & 2.81 & 1.090 & 2.78 & .997 \\
\hline
\end{tabular}

Note. $M=$ mean; $S D=$ standard deviation. 
standard deviation) were calculated using an alpha level of .05 in all statistical tests. The validation of the questionnaire was carried out by an exploratory factor analysis (EFA) with a total sample of 791 participants, 393 boys and 398 girls. Principal component extraction with varimax rotation was calculated in order to establish the integrity and independence of the CAIPE-SP subscales. Internal consistency of the subscales was measured by Cronbach's Alpha (Cronbach, 1951), carrying out bivariate correlations between subscales as well.

\section{Results}

Statistical data in the scale CAIPE-SP were analyzed separately based on the gender of participants. Descriptive analysis based on gender showed that girls had marginally higher mean values for the General subscale than boys. On the other hand, boys had marginally higher mean values for the Sport Specific subscale. Results of t-test computed taking into consideration gender are presented in Table 2. Outcomes of this analysis revealed no significant gender differences in CAIPE-SP sub-scales, according to the effect size Cohen's index. Correlations between the different sub-scales were around 0 , suggesting that there is no relationship between such variables.

Data related to mean and standard deviation of each item are shown in Table 1. A deeper analysis showed both boys and girls had higher whole scale scores than registered in previous studies (Block, 1995; Hutzler \& Levi, 2008) as well as only in the GPE subscale (Campos et al., 2013), showing a more positive attitude towards the inclusion of children with disabilities in GPE compared to attitudes shown in studies carried out in American, Israel or Portugal.

Similar to Block (1995) and Kudláček (2007), factor analysis was carried out using a main component factor analysis with Varimax rotation.
The obtained results confirmed a structure of three components of the scale CAIPE-SP (Table 3), accounting for $35.982 \%$ of the variance. This structure is not totally similar to the one found in the original scale CAIPE-R of Block (1995). This is because some items were structured in a different way. For example, item 2 (Because Juan needs help to play sports, he would slow down the game for everyone) was weakly loaded, suggesting that it should be excluded from the scale CAIPE-SP. Most items were loaded in their intended factors. GPE and sport specific sub-scales were clearly defined with five out of seven and three out of five loading on their intended factor. Items 2 and 5 , originally allocated to GPE sub-domain cross loaded in sport-specific sub-domain with low loading factors of .020 and .263 respectively, while items 9 and 11 originally allocated to sport specific sub-domains cross loaded in a new factor with loading factors of .516 and .510 respectively.

According to Hair, Anderson, Tatham and Black (2010), results showed by the CAIPE-SP demonstrated adequate internal consistency, based on a Cronbach's alpha of $\alpha=.621$ for the complete scale, obtaining, likewise, satisfactory reliability coefficient of $\alpha=.812$ for the General PE scale (F1). Otherwise, External Assistance scale (F2) and Sport-Specific Scale (F3) obtained a poor internal consistency, with coefficients of $\alpha=.470$ and $\alpha=.374$ respectively.

\section{Discussion}

As stated before, the purpose of this study was as follows:

1. Translate, carry out and validate a transcultural adaptation of the scale CAIPE-R into the Spanish language in order to be used in Spain.

2. Describe the structure of its components.

3. Compare the structure of CAIPE's Spanish version to the original instrument.

Table 2

Descriptive and t-test statistics for the sub-scales by gender

\begin{tabular}{|c|c|c|c|c|c|c|}
\hline \multirow{2}{*}{ Scale } & \multicolumn{2}{|c|}{$\mathrm{F} 1$} & \multicolumn{2}{|c|}{ F2 } & \multicolumn{2}{|c|}{ F3 } \\
\hline & Males & Females & Males & Females & Males & Females \\
\hline$M$ & 3.46 & 3.59 & 3.52 & 3.56 & 2.80 & 2.64 \\
\hline$S D$ & 0.78 & 0.63 & 0.82 & 0.74 & 1.08 & 0.99 \\
\hline$t$ & \multicolumn{2}{|c|}{-2.62} & \multicolumn{2}{|c|}{-0.65} & \multicolumn{2}{|c|}{2.03} \\
\hline$p$ & \multicolumn{2}{|c|}{$>.03$} & \multicolumn{2}{|c|}{ ns } & \multicolumn{2}{|c|}{ ns } \\
\hline$d$ & \multicolumn{2}{|c|}{-0.18655267} & \multicolumn{2}{|c|}{-0.04628215} & \multicolumn{2}{|c|}{0.1445} \\
\hline
\end{tabular}

Note. $\quad \mathrm{F} 1=$ General PE; F2 = External Assistance; F3 = Sport Specific; $M=$ mean; ns = not statistically significant; $S D=$ standard deviation. 
Table 3

Component loadings, eigenvalues and percentages of variance using principal component extraction with varimax rotation $(N=791)$

\begin{tabular}{|c|c|c|c|c|}
\hline \multirow{2}{*}{ Subscale } & \multirow{2}{*}{ Item Number } & \multicolumn{3}{|c|}{ Loadings } \\
\hline & & F1 & F2 & F3 \\
\hline \multirow{5}{*}{ General PE } & 1 & .699 & & \\
\hline & 3 & .733 & & \\
\hline & 4 & .652 & & \\
\hline & 6 & .559 & & \\
\hline & 7 & .602 & & \\
\hline \multirow{2}{*}{ External Assistance } & 9 & & .516 & \\
\hline & 11 & & .510 & \\
\hline \multirow{5}{*}{ Sport Specific } & 2 & & & {$[.020]$} \\
\hline & 5 & & & .263 \\
\hline & 8 & & & .252 \\
\hline & 10 & & & .571 \\
\hline & 12 & & & .506 \\
\hline Eigenvalue & & 3.520 & 1.636 & 1.095 \\
\hline$\%$ Variance & & 20.697 & 8.209 & 7.076 \\
\hline Cum. \% Variance & & 20.697 & 28.906 & 35.982 \\
\hline
\end{tabular}

4. Test the validity and reliability of the CAIPE's Spanish version.

5. Measure the attitudes of the sample regarding the inclusion of a classmate with disability in the physical education curricular area.

The translation was carried out according to the international standardized recommendations of Beaton et al. (2000), using the method of inverse translation (Banville et al., 2000; Hambleton, 1996), as well as in the translation of Campos et al. (2013), Hutzler and Levi (2008), or Kudláček et al. (2011). A committee of experts validated the adaptation and translation process, having a high acceptance opinion towards the new instrument, once translated and in comparison with the original CAIPE-R.

The study did not show significant differences regarding the gender, as boys and girls scored similarly, obtaining relatively high scores. This is in contrast to a number of publications about gender differences regarding the attitude towards an inclusion of people with disabilities (Panagiotou et al., 2008) that show girls tend to have more positive attitudes towards inclusion of peers with disabilities in GPE (Campos et al., 2013; Loovis \& Loovis, 1997; Slininger et al., 2000; Tripp, French, \& Sherrill, 1995; Van Biesen et al., 2006;). In deference to Fishbein (1996), we believe that, nowadays, girls are not socialized to be more responsible and nurturing toward dependent individuals than are boys, having a similar education by their families and the scholar system.

The CAIPE-SP showed an acceptable internal consistency, in line with the original CAIPE-R (Block, 1995). However, CAIPE-SP showed components with slightly different aggregation of items. Results obtained in the main component analysis provide a moderate support for the two main sub domain factor model of CAIPE-R found by Block (1995) or Hutzler and Levi (2008) that have been appeared in other studies from different cultural and educational settings. Instead, a structure of three factors in the factor analysis was found, just as in the research of Campos et al. (2013). They have been named (a) general beliefs about inclusion in physical education and (b) beliefs about sport specific rule modifications. A third factor has appeared, being composed by two items and being named External Assistance. This factor analysis confirms a structure of three components 
of the scale CAIPE-SP, accounting for $35.982 \%$ of the variance. In our view, the items 9 and 11, which compose the External Assistance factor require further investigation about the content meaning for the Spanish population. Both of them refer to the concept of counting on external help to provide support to the peer with disability. It could appear that Spanish students tend to be positive toward this idea, having obtained higher values that in the sentences contained in the original Sport Specific sub-scale. We believe that, for the Spanish students, the idea of helping the peers with disability is significantly more interesting that the idea of modifications to sport rules, which could explain the presence of this third factor. In our understanding, further research is needed in order to know more about those different cross loadings.

Results from Block's study showed Cronbach's Alpha values of .78 for the general attitude subscale and .67 for the sport specific subscale. Results from Hutzler and Levi (2008) revealed Cronbach's Alpha values of .77 for the general attitude subscale and .62 for the sport specific subscale. Research from Kudláček et al. (2011) reported a high internal consistency, obtaining Cronbach's Alpha value of .84 for the total scale. Likewise, results from Campos et al. (2013) showed a Cronbach's Alpha value of .72 for the general attitude subscale, and a much poorer Cronbach's Alpha value of .48. In the present study internal consistency has obtained a Cronbach's Alpha value of .812 for the general subscale and a much poorer .374 for the sport specific subscale, while getting a third factor with a reliability value of $\alpha=.470$. The global scale obtained a value of $\alpha=.621$. It could be stated that the general subscale obtained a good internal consistency, similar to those reported in other researches, while the sport specific subscale, similar as the Campos et al. (2013) results, obtained a lower than those previously reported in other research. It could be conjectured that the use of Kickball in the sport specific subscale promoted a misunderstanding by the Spanish students. While the choice of this sport for the subscale was made due to its similitude to the original scale sport and by its popularity in the Spanish schools, the use of other more popular sport among the Spanish students, as soccer, could have induced a better understanding, having obtained a higher value of internal consistency for this subscale. The fact that it is indubitable is that more research about this point must be carried out in the future.

The availability of the scale CAIPE-R in Spanish is a starting point for a wide part of the global population to start using this scale, which to date did not have such instrument in this language. Thus, following the path started by Block (1995), this scale provides the positive perspective of studying in depths the attitudes towards people with visual impairment, as well as carrying out an examination of attitudes towards the potential modification of norms in games and sports, and the inclusion of these people in the physical education curricular area. It will offer valuable information regarding the construction of a truly inclusive physical education to a group of countries and cultures that to date did not have the scale CAIPE in Spanish language.

\section{Conclusions}

Taking into account the obtained results, the transcultural adaptation of the scale CAIPE-R into Spanish supposes a valuable contribution to the research about the perception of disabilities in physical education. The instrument allows the assessment in a valid, reliable, easy and fast way of students` perception towards visual impairment, as well as towards the integration of people with that disability in the area of general physical education. A limitation of the new CAIPE-SP is that, just as the version CAIPE-CZ (Kudláček et al., 2011), it does not include a vignette in the description of the student with disability. On the one hand, it has been considered that it would not be necessary to create the idea of a student with visual impairment. On the other hand, it has been considered that this graphic illustration could have distorted the opinion of the students, as they would have focused on their limitations, affecting negatively to their objective answers in the questionnaire. Besides, the low Cronbach's Alpha of the Sport Specific Factor require further research, in order to study how could we increase it. The objectives of future lines of research are as follows:

a) to carry out different versions of this questionnaire oriented to other disabilities;

b) to carry out different transcultural adaptations of the scale to Spanish-speaking countries in South America; and

c) to use a different sport in the items of Sport Specific subscale, perhaps soccer.

\section{References}

Aguado, A. L., Flórez, M. A., \& Alcedo, M. A. (2004). Programas de cambio de actitudes ante la discapacidad [Programmes of change of attitudes towards disability]. Psicothema, 16(4), 667-673. 
Banville, D., Desrosiers, P., \& Genet-Volet, Y. (2000). Translating questionnaires and inventories using a cross-cultural translation technique. Journal of Teaching in Physical Education, 19, 374-378.

Beaton, D., Bombardier, C., Guillemin, F., Ferraz, M. B. (2000). Guidelines for the process of cross-cultural adaptation of self-report measures. Spine, 25, 3186-3191.

Block, M. E. (1995). Development and validation of the children's attitudes toward integrated physical educationrevised (CAIPE-R) Inventory. Adapted Physical Activity Quarterly, 12, 60-77.

Block, M. E. (2016). A teachers'guide to adapted physical education (4th ed.). Baltimore (MD): Paul H. Brookes.

Block, M. E., \& Malloy, M. (1998). Attitudes of girls towards including a child with severe disabilities in a regular fastpitch softball league. Mental Retardation, 36, 137-144.

Block, M. E. (2007). A teachers' guide to including students with disabilities in general physical education (3rd ed.). Baltimore (MD): Paul H. Brookes.

Block, M. E., \& Obrusníková, I. (2007). Inclusion in physical education: A review of the literature from 1995-2005. Adapted Physical Activity Quarterly, 24, 103-124.

Block, M. E., \& Obrusnikova, I. (2016). What is Inclusion? In M. E. Block (Ed.), A teacher's guide to adapted physical education (4th ed.) (pp. 19-34). Baltimore (MD): Paul H. Brookes.

Campos, M. J., Ferreira, J. P., \& Block, M. E. (2013). An analysis into the structure, validity and reliability of the children's attitudes towards integrated physical education-revised (CAIPE-R). European Journal of Adapted Physical Activity, 6(2), 29-37.

Carretero-Dios, H., \& Pérez, C. (2007). Standars for the development and reviw of instrumental studies: Considerations about test selection in psychological research. International Journal of Clinical and Health Psychology, 7(3), 863-882.

Cordente, D., González-Villora, S., Pastor-Vicedo, J. C., \& Contreras-Jordán, O. R. (in press). Diseño y validación de un cuestionario para valorar las actitudes de los escolares hacia la discapacidad visual [Design and validation of a students attitudes towards visual impairment questionnaire]. Cuadernos de Psicología del Deporte.

Cronbach, J. L. (1951). Coefficient alpha and the internal structure of tests. Psychometrika 22(3), 297-334.

Ellery, J. P., \& Rauschenbach, J. (2000). Impact of disability awareness activities on nondisabled student attitudes toward integrated physical education with students who use wheelchairs. Research Quarterly for Exercise and Sport, Supplement, Abstracts of Completed Research, 71(1), A-106.

European Comission. (2010). Una estrategia para un crecimiento inteligente, sostenible e integrador. [An strategy for an intelligent, sustainable and integrating growth] Bruselas: European Comission.

Fishbein, H. D. (1996). Peer prejudice and discrimination: Evolutionary, cultural and developmental dynamics. Boulder, CO: Westview.

Goodwin, D. L., \& Watkinson, E. J. (2000). Inclusive physical education from the perspective of students with physical disabilities. Adapted Physical Activity Quarterly, 17(2), 144-160.

Hair, J. F., Anderson, R. E., Tatham, R. L., \& Black, W. C. (2010). Multivariate data: Analysis with readings. Englewood Cliffs (NJ): Prentice-Hall.
Hambleton, R. K. (1996). Adaptación de tests para su uso en diferentes idiomas y culturas: fuentes de error, posibles soluciones y directrices prácticas. [Test Adaptation for their use in different languages and cultures: mistakes, solutions and practival guidelines]. In J. Muñiz (coord.), Psicometría (pp. 208-238). Madrid: Universitas.

Hutlzer, Y., Fliess, O., Chacham, A., \& Van den Auweele, Y. (2002). Perspectives of children with physical disabilities on inclusion and empowerment: Supporting and limiting factors. Adapted Physical Activity Quarterly, 19, 300-317.

Hutzler, Y., \& Levi, I. (2008). Including children with disability in physical education: general and specific attitudes of highschool students. European Journal of Adapted Physical Activity, 1(2), 21-30.

IPC. (2006). Paralimpic School Day Manual. Available at: http://www.paralympic.org/release/Main_Sections_Menu/ Education/Manual.html (accessed 5 February 2016).

Ješina, O., Lucas, S., Kudláček, M., Janečka, Z., Machová, I., \& Wittmannová, J. (2006). The effect of the Paralympic school day program on children's attitudes towards inclusion of children with disabilities in the Czech Republic. In Wittmannová, J. (ed.). Eucapa 2006 (p. 48). Olomouc: Univerzita Palackého v Olomouci.

Klavina, A., \& Kudláček, M. (2011). Physical education for students with special education needs in Europe: Findings of the EUSAPA project. European Journal of Adapted Physical Activity, 4(2), 46-62.

Kudláček, M. (2006). State of knowledge about inclusion of children with disabilities into general physical education. 8th European Conference of Adapted Physical Activity. Retrieved from http://www.eufapa.upol.cz/www/eucapa2006/ full/kudlacek1.pdf

Kudláček, M. (2007). Components of attitudes toward inclusion of students with physical disabilities in physical education in the revised „ATIPDPE-R“ instrument / scale for prospective Czech educators. Acta Universitatis Palackianae Olomucensis. Gymnica, 37(1), 13-18.

Kudláček, M., Ješina, O., \& Wittmanová, J. (2011). Structure of a questionnaire on childrens attitudes towards inclusive physical education (CAIPE-CZ). Acta Universitatis Palackianae Olomucensis Gymnica, 41(4), 43-48.

Lienert, C., Sherrill, C., \& Myers, B. (2001). Physical educators' concerns about integrating children with disabilities: A cross cultural comparison. Adapted Physical Activity Quarterly, 18(1), 1-17.

Lindsay, S., \& McPherson, A. C. (2012). Experiences of social exclusion and bullying at school among children and youth with cerebral palsy. Disability and Rehabilitation, 34, 101-109.

Lipsky, D., \& Gartner, A. (1997). Inclusion and School reform: Transforming America's classrooms. Baltimore (MD): Paul H. Brookes.

Liu, Y., Kudláček, M., \& Ješina, O. (2010). The influence of Paralympic school day on children's attitudes toward people with disabilities. Acta Universitatis Palackianae Olomucensis Gymnica, 40(2), 63-69.

Loovis, E. M., \& Loovis, C. L. (1997). A disability awareness unit in physical education and attitudes of elementary school students. Perceptual and Motor Skills, 84, 768-770.

McKay, C., Block, M. E., \& Park, J. Y. (2015). The impact of Paralympic School Day on student attitudes toward 
inclusion in physical education. Adapted Physical Activity Quarterly, 32, 331-348.

Meegean, S., \& MacPhail, A. (2006). Irisih physical educators' attitude toward teaching students with special educational needs. European Physical Education Review, 12(1), 75-97.

Modell, S. J. (2007). Student perceptions about sports for persons with physical disabilities - an exploratory study. Palaestra, 23(3), 32-37.

Murata, N. M., Hodge, S. R., \& Little, J. R. (2000). Students attitudes, experiences, and perspectives on their peers with disabilities. Clinical Kinesiology, 54(3), 59-66.

Obrusnikova, I., Block, M. E., \& Dillon, S. (2010). Children`s beliefs toward cooperative playing with peers with disabilities in physical education. Adapted Physical Activity Quarterly, 27(2), 127-142.

Obrusníková, I., Válková, H., \& Block, M. E., (2003). Impact of inclusion in general physical education on students without disabilities: Preliminary investigation. Adapted Physical Activity Quarterly, 20, 230-245.

Panagiotou, A. K., Evaggelinou, C., Doulkeridou, A., Mouratidou, K., \& Koidou, E. (2008). Attitudes of 5th and 6th grade Greek students toward the inclusion of children with disabilities in physical education classes after a paralympic education programme. European Journal of Adapted Physical Activity, 1(2), 31-43.

Pérez-Tejero, J. (2013). Centro de estudios sobre deporte inclusivo. Cuatro años de fomento del deporte inclusivo a nivel práctico, académico y científico. [Centre of Inclusive Sport. Four years of promoting inclusive sports]. Madrid: Universidad Politécnica de Madrid, Sanitas and Psysport.

Pérez-Tejero J., Ocete, C., Ortega-Vila, G., \& Coterón, J. (2012). Diseño y aplicación de un programa de práctica deportiva inclusiva y su efecto sobre la actitud hacia la discapacidad: El campus inclusivo de baloncesto. [Design and aplication of a inclusive sport-based programme and it effect on the attitude toward disability]. Revista Internacional de Ciencias del Deporte, 29(8), 258-271.

Place, K., \& Hodge, S. R. (2001). Social inclusion of students with physical disabilities in general physical education: A behavioral analysis. Adapted Physical Activity Quarterly, 18, 389-404.

Reina, R., Mendoza, N., Sanz, D., \& Pérez-Tejero, J. (2013). DAFA-WEB: An Internet site to promote adapted sports. Book of abstracts from 19th International Symposium of Adapted Physical Activity. Istanbul, 18-23 July 2013.

Slininger, D., Sherrill, C., \& Jankowski, C. (2000). Children's attitudes towards peers with severe disabilities: revisiting contact theory. Adapted Physical Activity Quarterly, 17(2), 176-196.

Smith, A. (2004). The inclusion of pupils with special educational needs in secondary school physical education. Physical Education and Sport Pedagogy, 9(1), 37-53.

Spanish Ministry of Education, Culture and Sports. (2006). Ley Orgánica 2/2006 de 3 de Mayo de Educación. [Organic Law of Education 2/2006]. BOE 106, May 4th 2006. Madrid: Gobierno de España.

Spanish Ministry of Education, Culture and Sports. (2013). Ley Orgánica 8/2013 de 9 de Diciembre de Educación. [Organic Law of Education 8/2013]. BOE 295, December 10th 2013. Madrid: Gobierno de España.

Spanish Ministry of Education, Culture and Sports. (2014a).
Datos y cifras. Curso escolar 2014/2015. [2014/2015 Academic Term. Facts and Figures]. Available at: http://www. mecd.gob.es/servicios-al-ciudadano-mecd/dms/mecd/servicios-al-ciudadano-mecd/estadisticas/educacion/indicadorespublicaciones-sintesis/datos-cifras/Datosycifras 1415.pdf (accessed 7 February 2016).

Spanish Ministry of Education, Culture and Sports. (2014b). Estadística de las enseñanzas no universitarias. Alumnado con necesidad específica de apoyo educativo. Curso 2012-2013. [2012/2013 Academic Term. Facts and Figures of the non-university education. Special Educational Needs Students]. Available at: http://www.mecd.gob.es/dms/mecd/ servicios-al-ciudadano-mecd/estadisticas/educacion/no-universitaria/alumnado/Necesidades-de-apoyo/Curso1213/ NotaResumen.pdf (accessed 5 February 2016).

Tripp, A., French, R., \& Sherrill, C. (1995). Contact theory and attitudes of children in physical educators programmes towards peers with disabilities. Adapted Physical Activity Quarterly, 12, 323-332.

Townsend, M., \& Hassall, J. (2007). Mainstream students‘ attitudes to possible inclusion in unified sports with students who have an intellectual disability. Journal of Applied Research in Intellectual Disabilities, 20(3), 265-273.

United Nations (2006). Convention on the Rights of Persons with Disabilities and Optional Protocol. New York (NY): United Nations.

U.S. Department of Education (2008). To assure the free appropiate public education of all children with disabilities: Twenty-eight annual report to Congress on the implementation of the Individuals with Disabilities Education Act. Washington, DC.

U.S. Department of Education (2013). Digest of Education Statistics, 2012. Washington, DC: National Center for Education Statistics. (NCES 2014-015).

Van Biesen, D., Busciglio, A., \& Vanlandewijck, Y. (2006). Attitudes towards inclusion of children with disabilities: the effect of the implementation of „A Paralympic School Day“ on Flemish elementary children. 8th European Conference of Adapted Physical Activity. Available at: http://www. eufapa.upol.cz/index.php/eucapa/proceedings/eucapa-2006. html (accessed 12 February 2016).

Verderber, J. M., Rizzo, T. L., \& Sherrill, C. (2003). Assessing student intention to participate in inclusive physical education. Adapted Physical Activity Quarterly, 20(1), 26-45.

Verdugo, M. A. (2009). El cambio educativo desde una perspectiva de calidad de vida. Monográfico. [The educational change from a quality of life view]. Revista de Educación, $349,23-43$.

WEAC. (2009). Special Education Inclusion. Available at: http://www.weac.org/Issues_advocacy/Resource_Pages_ On_Issues_One/Special_Education/special_education_inclusion.aspx (accessed 11 February 2016).

Xafopoulos, G., Kudláček, M., Evaggelinou, C. (2009). Effect of the intervention programme „Paralympic Sport Day" on attitudes of children attending international school towards inclusion of students with disabilities. Acta Universitatis Palackianae Olomucensis. Gymnica, 39(4), 63-71.

\section{Corresponding author}

David Cordente-Mesas

Email address | davidcordente@gmail.com 